\title{
Oral administration of deuterium-labelled polyamines to sucking rat pups: luminal uptake, metabolic fate and effects on gastrointestinal maturation
}

\author{
BY BERNARD DORHOUT ${ }^{1}$, ANET VAN FAASSEN ${ }^{1}$, CHRISTIEN M. VAN BEUSEKOM $^{1}$, \\ ANNEKE W. KINGMA ${ }^{1}$, ELLY DE HOOG ${ }^{1}$, GIJS T. NAGEL ${ }^{1}$, AREND KARRENBELD ${ }^{2}$, \\ E. RUDY BOERSMA ${ }^{3}$ AND FRITS A. J. MUSKIET ${ }^{1}$ \\ ${ }^{1}$ Central Laboratory for Clinical Chemistry, ${ }^{2}$ Department of Pathology, and ${ }^{3}$ Department of Obstetrics \\ and Gynaecology, Nutrition \& Development Unit, University and University Hospital Groningen, \\ Oostersingel 59, PO Box 30.001, 9700 RB Groningen, The Netherlands
}

(Received 16 July 1996 - Revised 27 January 1997 - Accepted 19 March 1997)

\begin{abstract}
Non-physiological amounts of oral polyamines have been reported to induce precocious gut maturation in rat pups. The aim of the present study was to investigate organ distribution and metabolic fate of orally administered stable-isotopically labelled polyamines in rat pups. Pups received tetradeuterium-labelled putrescine (Pu-d4; $3 \mu \mathrm{mol}$ ), spermidine (Sd-d4; $5 \mu \mathrm{mol}$ ), spermine (Sp-d4; $3 \mu \mathrm{mol}$ ), or physiological saline twice daily on postnatal days 7-10 or 12-15. They were killed on days 10 and 15 . We determined activities of ileal lactase (EC 3.2.1.23), maltase $(E C$ 3.2.1.20), sucrase $(E C$ 3.2.1.48) and diamine oxidase (EC 1.4.3.6) and established villus and crypt lengths. Polyamines and their labelling percentages in organs were determined by GC and mass fragmentography. Treatments did not affect growth rate, but caused lower weights of liver, kidneys and heart. Maltase activity increased, lactase decreased, whereas sucrase and diamine oxidase did not change. Villus and crypt lengths increased. Organ polyamine pools were labelled to different extents. Irrespective of the orally administered polyamine, all organs contained Pu-d4, Sd-d4 and Sp-d4. Administered Pu-d4 and Sd-d4 were recovered mainly as Sd-d4, whereas Sp-d4 was recovered as Sp-d4 and Sd-d4. Total polyamines in a caecum, colon and erythrocytes increased, but increases were only to a minor extent with regard to labelled polyamines. Our data confirm precocious gut maturation by exogenous polyamines. Putrescine appears to be the limiting factor. The exogenous polyamines were distributed among all investigated organs. They are not only used for the synthesis of higher polyamines, but also retroconverted to their precursors. Changes in erythrocyte polyamine contents suggest precocious stimulation of erythropoiesis.
\end{abstract}

Polyamines: Gut maturation: Metabolism

Polyamines are organic polycations that are present in all mammalian cells (Pegg \& McCann, 1982). Although many of their functions have yet to be elucidated it has been firmly established that they are essential to cell proliferation and differentiation. Cellular polyamine homeostasis is maintained through endogenous biosynthesis, polyamine-retroconversion (Seiler et al. 1981), terminal catabolism and uptake from extracellular sources (Seiler \& Dezeure, 1990). Proliferating cells have high polyamine contents. In the event of rapid growth (e.g. pregnancy, early postnatal life, tissue regeneration, malignant processes), de novo biosynthesis and supply from extracellular sources may be insufficient to maintain polyamine homeostasis. The gastrointestinal (GI) tract is the major extracellular polyamine source. GI polyamines derive either from the diet or from the bacterial flora (Hessels et al. 1989; Sarhan et al. 1989; Satink et al. 1989). Osborne \& Seidel (1990) 
reported that polyamines are absorbed through a carrier-mediated uptake process and that they enter the enterohepatic cycle. Recently, Bardócz et al. (1995) showed that orally administered ${ }^{14} \mathrm{C}$-labelled polyamines are absorbed in adult rats, presumably by passive diffusion.

In rats, but also in human subjects, after birth the GI tract undergoes major histological and biochemical changes. In early neonatal life, macromolecules are absorbed both by nonspecific and by receptor-mediated mechanisms (Jones \& Waldman, 1972; Gonnella et al. 1987; Hasegawa et al. 1987). Gut maturation leads, for example, to closure of epithelial tight junctions. As a result, non-specific macromolecular transfer across the epithelial membrane ceases. During gut maturation sucrase (EC 3.2.1.48) and maltase (EC 3.2.1.20) activities rise, whereas lactase ( $E C$ 3.2.1.23) activity decreases. Gut maturation is also expressed by increasing villus length and by disappearance of the supranuclear vacuole and the apical canalicular system in enterocytes. The latter event results in cessation of nonspecific protein transfer.

Non-physiological amounts of oral polyamines induce precocious gut maturation in rat pups (Dufour et al. 1988; Buts et al. 1993; Capano et al. 1994; Harada et al. 1994). Non-specific protein transfer decreases (Capano et al. 1994; Harada et al. 1994) and disaccharidase activities change towards a mature profile (Romain et al. 1992). Disaccharidase activities may also mature following corticosteroid-induced changes in endogenous polyamine metabolism (Nsi-Emvo et al. 1996). Recently, we estimated that human milk: maternal plasma ratios for putrescine, spermidine and spermine range between 16 and 19, 14 and 24, and 44 and 75 respectively (Dorhout et al. 1996). Formula milk contains significantly less polyamine than maternal milk (Pollack et al. 1992; Romain et al. 1992; Buts et al. 1995). Considering the effects of polyamines on GI tract maturation, it may be postulated that milk polyamines have physiological significance and that their addition to formula milk may be important to maintain cellular polyamine homeostasis.

To obtain insight into the fate and possible physiological significance of dietary polyamines in early neonatal life, we determined the distribution and metabolism of orally administered, stable-isotopically labelled polyamines in rat pups. The treatment protocol was according to Dufour et al. (1988), with some minor modifications. Changes in gut maturation were investigated by measurement of ileal disaccharidase (lactase, maltase and sucrase) activities. We additionally studied small-intestinal diamine oxidase (EC 1.4.3.6; DAO) activity. DAO catabolizes histamine, putrescine and cadaverine, and shows an agedependent pattern (Luk et al. 1980). Morphometric determinations of the villus and crypt lengths were used as other indicators of GI tract maturation.

\section{MATERIALS AND METHODS}

\section{Chemicals}

Heptafluorobutyric acid anhydride and Tri-sil-TBT were obtained from Pierce (Rockford, IL, USA). Cadaverine, aminoguanidine (AG), DAO, sucrose, maltose monohydrate, trehalose dihydrate, galactose, glucose and fructose were from Sigma (St Louis, MO, USA). Perseitol was obtained from Pfanstiehl Laboratories (Waukegan, IL, USA). Chromtrioxide was from BDH Laboratory Reagents (Poole, Dorset). Ethyl acetate was obtained from Rathburn (Walkerburn, Scotland) and acetone, succinodinitrile and lactose monohydrate were from Merck (Darmstadt, Germany). $\gamma$-Aminobutyraldehyde-diethylacetal and maleic acid were obtained from Janssen (Beerse, Belgium) and acrylonitrile was 
from Aldrich (Beerse, Belgium). Orthoaminobenzaldehyde was synthesized by Syncom (Groningen, The Netherlands).

\section{Synthesis of tetradeuterated (d4) polyamines}

Putrescine-d4 (Pu-d4; $\mathrm{H}_{2} \mathrm{NCD}_{2} \mathrm{CH}_{2} \mathrm{CH}_{2} \mathrm{CD}_{2} \mathrm{NH}_{2}$ ) was prepared by catalytic reduction of its dicyano precursor succinodinitrile with deuterium gas. Spermidine-d4 (Sd-d4; $\mathrm{H}_{2} \mathrm{NCD}_{2} \mathrm{CH}_{2} \mathrm{CH}_{2} \mathrm{CD}_{2} \mathrm{NHCH}_{2} \mathrm{CH}_{2} \mathrm{CH}_{2} \mathrm{NH}_{2}$ ) and spermine-d4 (Sp-d4; $\mathrm{H}_{2} \mathrm{NCH}_{2} \mathrm{CH}_{2} \mathrm{CH}_{2}$ $\mathrm{NHCD}_{2} \mathrm{CH}_{2} \mathrm{CH}_{2} \mathrm{CD}_{2} \mathrm{NHCH}_{2} \mathrm{CH}_{2} \mathrm{CH}_{2} \mathrm{NH}_{2}$ ) were synthesized by cyanoethylation of $\mathrm{Pu}-\mathrm{d} 4$ with acrylonitrile, followed by catalytic reduction of the crystallized mono- and dicyano intermediates with $\mathrm{H}_{2}$ gas (Smith \& Daves, 1977). Sd-d4 and Sp-d4 were separated on a Dowex 50W $\times 8$ (mesh 200-400; Serva, Heidelberg, Germany) column by gradient elution with $\mathrm{HCl}$. Relative labellings were assessed by gas chromatography-mass spectrometry (see p. 642) and were found to be approximately $100 \%$ for Pu-d4, Sd-d4 and Sp-d4.

\section{Animals}

Four pregnant Wistar rats (Harlan, Zeist, The Netherlands) were housed under standard animal laboratory conditions $\left(25^{\circ}, 12 \mathrm{~h}\right.$ light-12 h dark cycle, food and water ad libitum). Day of birth of the rat pups was designated day 0 . In rat nests exceeding eight pups, pup numbers were reduced to eight.

\section{Experimental}

Four pups from one nest received twice daily $25 \mu$ physiological saline $(9 \mathrm{~g} \mathrm{NaCl} / \mathrm{l}$; PS; controls) from day 7 to day 10. Similarly, four pups from three other nests received: $3 \mu \mathrm{mol} \mathrm{Pu}-\mathrm{d} 4$ in $25 \mu \mathrm{l} \mathrm{PS} ; 5 \mu \mathrm{mol} \mathrm{Sd-d4}$ in $25 \mu \mathrm{l}$ PS; or $3 \mu \mathrm{mol} \mathrm{Sp-d4}$ in $25 \mu \mathrm{l} \mathrm{PS}$ respectively. Treatments were given at 10.00 and 15.00 hours. Pups were weighed twice daily. On day 10 , the pups received treatment at 10.00 hours and were killed immediately afterwards. On days $12-15$, the remaining four pups from each nest received the same treatments, with the exception that $50 \mu \mathrm{l}$ PS was used instead of $25 \mu \mathrm{l}$. These pups were killed on day 15.

Blood was collected by aortic puncture and centrifuged $\left(10 \mathrm{~min}, 1500 \mathrm{~g}, 4^{\circ}\right)$. Plasma was collected, frozen in liquid $\mathrm{N}_{2}$ and stored at $-20^{\circ}$ until polyamine analysis. The erythrocytes were washed three times with $3 \mathrm{ml}$ ice-cold phosphate-buffered saline (PBS). After each centrifugation step, the buffy coat was removed as completely as possible. Erythrocytes were finally suspended in PBS to a packed cell volume of about $50 \%$, counted with an electronic particle counting device (Coulter Electronics, Mijdrecht, The Netherlands), frozen in liquid $\mathrm{N}_{2}$ and stored at $-20^{\circ}$ until polyamine analysis.

Kidneys, spleen, heart, liver and brain (for Pu-d4 and control only) were isolated, weighed, frozen in liquid $\mathrm{N}_{2}$ and stored at $-20^{\circ}$ until polyamine analysis. After collection, the jejunum (day 10: 60-140 mm distal from the stomach; day 15: 75-220 mm distal from the stomach), caecum and colon were thoroughly rinsed with ice-cold PBS, frozen in liquid $\mathrm{N}_{2}$ and stored at $-20^{\circ}$ until polyamine analysis. The ileum was isolated and rinsed thoroughly with ice-cold PBS. The most distal $10 \mathrm{~mm}$ of the ileum was rinsed thoroughly with ice-cold PBS and used for histological examination (see p. 643). The remainder of the ileum (day 10: 140-290 mm distal from the stomach; day 15: 220-350 mm distal from the stomach) was cut into three equal parts. The proximal part was used for the analysis of disaccharidase activity, the middle for polyamine analysis, and the distal part for DAO 
activity analysis. All parts were frozen in liquid $\mathrm{N}_{2}$. The proximal and distal parts were subsequently stored at $-80^{\circ}$ until enzyme activity analysis, whereas the mid-part was stored at $-20^{\circ}$ until polyamine analysis.

\section{Measurement of polyamines}

Polyamines were determined by capillary GC with N-P detection, essentially as previously described (Muskiet et al. 1984; Van den Berg et al. 1987). Briefly, tissues were homogenized in $0.55 \mathrm{M}$-sulfosalicylic acid and erythrocytes were sonicated. All samples were deproteinized by addition of $0.55 \mathrm{M}$-sulfosalicylic acid. They were frozen at $-20^{\circ}$ for at least $1 \mathrm{~h}$, thawed and centrifuged. Supernatant fractions were used for polyamine analyses. For this, polyamines were isolated by adsorption to silica and converted into their heptafluorobutyryl derivatives.

\section{Measurement of polyamine labelling percentages}

Polyamine labelling percentages were determined essentially as previously described (Van den Berg et al. 1984). For putrescine and spermidine we used a Hewlett Packard Model 5890 GC (Amstelveen, The Netherlands) directly coupled with a VG Masslab Trio-2 quadrupole mass spectrometer (Manchester, Greater Manchester). The system was operated under the following conditions: injector temperature $280^{\circ}$; splitless injection mode; He flow rate $1 \mathrm{ml} / \mathrm{min}$; oven temperature program $100^{\circ}, 20^{\circ} / \mathrm{min}$ to $280^{\circ}, 6 \mathrm{~min}$ at $280^{\circ} ; \mathrm{NH}_{3}$ chemical ionization mode; ionization energy $70 \mathrm{eV}$; source temperature $250^{\circ}$; capillary fused silica column (length $25 \mathrm{~m}$, diameter $0.25 \mathrm{~mm}$, film thickness $0.11 \mathrm{~mm}$; CP Wax 52CB (Chrompack, Middelburg, The Netherlands). The positive ions at $\mathrm{m} / \mathrm{z} 498$ and 751 (corresponding to the $[\mathrm{M}+18]^{+}$ions of the heptafluorobutyryl derivatives of naturally occurring putrescine and spermidine respectively), and 502 and 755 (corresponding to the $[\mathrm{M}+18]^{+}$ions of the $\mathrm{Pu}-\mathrm{d} 4$ and $\mathrm{Sd}-\mathrm{d} 4$ derivatives respectively) were monitored.

Labelling percentages of spermine were determined with a Hewlett Packard Model 5890 GC directly coupled with a VG Analytical 70-250 S Magnet Sector mass spectrometer. The system was operated as described earlier, with the exception of column (capillary fused silica column; length $25 \mathrm{~m}$; diameter $0.25 \mathrm{~mm}$; film thickness $0.11 \mathrm{~mm}$; CP Sil 19CB from Chrompack) and ionization mode (electron-impact at $70 \mathrm{eV}$ ). The positive ions at m/z 789 and 793 (corresponding to the $[\mathrm{M}-197]^{+}$fragments of the heptafluorobutyryl derivatives of naturally occurring spermine and Sp-d4 respectively) were monitored.

The peak area ratios 502: 498 (Pu-d4:Pu-d0), $755: 751$ (Sd-d4:Sd-d0) and $793: 789$ (Sp-d4 : Sp-d0), at the corresponding retention times of the heptafluorobutyryl derivatives of putrescine, spermidine and spermine respectively, were calculated with a VG Analytical 11-250 I datasystem. Labelling percentages were calculated from peak area ratios by comparison with those of standards, plotted in a calibration curve.

\section{Measurement of disaccharidase activities}

Lactase, maltase and sucrase activities were determined in the proximal section of the ileum, essentially as described by Dahlqvist (1964). Ileum tissue was homogenized (Potter apparatus, Braun Melsungen AG, Germany) in four volumes of PS and centrifuged $\left(1000 \mathrm{~g}, 10 \mathrm{~min}, 4^{\circ}\right)$. For the determination of the sucrase and maltase activities, supernatant fractions were diluted 10-fold in maleic acid buffer, $\mathrm{pH}$ 6. We added $100 \mu \mathrm{l}$ 
sucrose solution ( $56 \mathrm{mM}$ in maleic acid buffer, $\mathrm{pH} \mathrm{6}$ ) to $100 \mu \mathrm{l} 10$-fold diluted supernatant fraction for the assay of sucrase activity, and $100 \mu \mathrm{l}$ maltose solution (56 mM in maleic acid buffer, $\mathrm{pH} 6$ ) to $10 \mu \mathrm{l} 10$-fold diluted supernatant fraction for the assay of maltase activity. For the assay of lactase activity, the supernatant fraction of the tissue homogenate was diluted 10-fold in maleic acid buffer, pH 5.2. Lactose solution (100 $\mu \mathrm{l} ; 56 \mathrm{mM}$ in maleic acid buffer, $\mathrm{pH} 5.2$ ) was added to $50 \mu \mathrm{l}$ of this diluted supernatant fraction.

One drop of toluene was added to each of the reaction mixtures. Following incubation at $37^{\circ}$ for $60 \mathrm{~min}$, the reactions were stopped by the addition of $800 \mu \mathrm{l}$ methanol. Samples were deproteinized by storage at $-20^{\circ}$ overnight. After thawing, $200 \mathrm{nmol}$ perseitol and $1000 \mathrm{~nm}$ trehalose were added as internal standards for the assay of monosaccharides and disaccharides respectively.

Monosaccharides were quantified by GC with flame ionization, essentially as described by Jansen $e t$ al. (1986). Briefly, supernatant fractions were washed with $4 \mathrm{ml}$ hexane. The supernatant fraction was subsequently evaporated to dryness, and trimethylsilylated with Trisil-TBT. The derivatives were dissolved in $1 \mathrm{ml}$ water and subsequently extracted with $2 \mathrm{ml}$ hexane. The hexane layer was washed with $2 \mathrm{ml} 0.1 \mathrm{M}-\mathrm{HCl}$, dried with anhydrous $\mathrm{Na}_{2} \mathrm{SO}_{4}$, and injected into the GC. Monosaccharide formation rate was expressed in terms of the protein content of the supernatant fraction (Lowry et al. 1951) and tissue wet weight.

\section{Measurement of diamine oxidase activity}

DAO activity in the distal section of the ileum was determined essentially as described by Biondi et al. (1984). The principle is based on the conversion of cadaverine to $\Delta^{1}$ piperideine, which is the cyclic product of cadaverine oxidative deamination by DAO. Tissue was homogenized (Potter apparatus) in ice-cold phosphate buffer $(0.15 \mathrm{M} ; \mathrm{pH} 8.0)$ and centrifuged $\left(2000 \mathrm{~g} ; 15 \mathrm{~min} ; 4^{\circ}\right)$. We added $100 \mu \mathrm{l}$ cadaverine solution $(5 \mathrm{mM}$ in $0.15 \mathrm{M}$-phosphate buffer, $\mathrm{pH} 8.0$ ) to $1.0 \mathrm{ml}$ of the supernatant fraction. The mixture was incubated at $37^{\circ}$ for $15 \mathrm{~min}$. The reaction was stopped by the addition of $0.6 \mathrm{M}$-TCA. $\Delta^{1}$ Pyrroline was added as an internal standard. $\Delta^{1}$-Piperideine and $\Delta^{1}$-pyrroline were converted into 2,3-tetramethylene-4-quinazolone and 2,3-trimethylene-4-quinazolone by coupling with $o$-aminobenzaldehyde and subsequent oxidation with $\mathrm{Cr}_{2} \mathrm{O}_{3}$ in $2 \mathrm{M}-\mathrm{H}_{2} \mathrm{SO}_{4}$. These chromophores were separated and detected by HPLC-spectrophotometry at $268 \mathrm{~nm}$. Calibration was done by comparison of peak area ratios with those of standards. Standards were prepared by incubating excess porcine DAO (100 nmol cadaverine/min) with 20,40 , 60 and $80 \mathrm{nmol}$ cadaverine respectively, during $1 \mathrm{~h}$. DAO activity was expressed as a ratio to total protein.

\section{Measurement of villus and crypt lengths}

The distal $10 \mathrm{~mm}$ of the ileum was rinsed thoroughly with ice-cold PBS, fixed in $4 \%$ formaldehyde, and embedded in paraffin. Sections $(5 \mu \mathrm{m})$ were cut and stained with haematoxylin-eosin. Villus and crypt lengths were analysed in well-oriented cross-sections by light microscopy. For each animal we analysed at least forty crypt-villus units.

\section{Statistics}

Differences in organ weights, enzyme activities, polyamine levels and villus and crypt lengths were analysed with Student's unpaired two-tailed $t$ test, corrected for type I errors 
at $P<0.05$ (Stevens, 1986). Statistical evaluation of differences in growth rate were performed using profile analysis with repeated measurements at $P<0.05$ (Stevens, 1986).

\section{RESULTS}

\section{Effects on growth rate and organ weights}

Growth rate was not affected by either of the polyamine treatments (results not shown). The growth curves were found to be parallel, but not coincident. Table 1 shows organ weights on days 10 and 15 after treatment with Sd-d4 and Sp-d4 on days 7-10 and 12-15 respectively. Organ weights of Pu-d4 treated animals were not assessed. On day 10 liver weight was lower after both spermidine and spermine treatments, whereas heart weight was lower after spermine treatment. On day 15 , both spermidine- and spermine-treated pups had lower kidney and heart weights.

\section{Relative labelling}

Fig. 1 shows the relative contributions of the sum of all labelled polyamines to the total polyamine pools in various rat pup organs on days 10 and 15. All investigated organs contained labelled polyamines, but the pools were labelled to different extents. In general, gut polyamine pools were more heavily labelled than those of other tissues, reaching a maximum of $45 \%$ label in ileum on day 10 after Sd-d4 treatment. Erythrocytes and plasma generally contained the lowest labelling percentages, with maximum erythrocyte labelling of $15 \%$ on day 10 after Sd-d4 treatment. Brain (not shown in Fig. 1) contained 6.9 (SD 1.5 ) \% and 2.0 (SD 0.3) \% labelled polyamines after treatment with Pu-d4 on days 7-10 and 12-15 respectively.

\section{Effects on tissue polyamine contents}

Changes in tissue polyamine contents as a result of oral polyamine administration were generally similar when they were given on days 7-10 and days $12-15$ (Table 2). The most striking changes were observed in gut tissue and erythrocytes. Polyamine contents

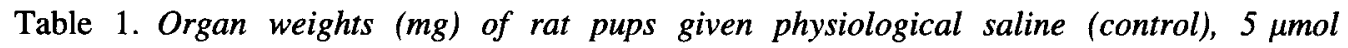
deuterium-labelled spermidine (Sd-d4) or $3 \mu \mathrm{mol}$ deuterium-labelled spermine (Sp-d4) twice daily on days 7-10 or 12-15 postpartum $\dagger$

(Mean values and standard deviations for four pups per group on each day)

\begin{tabular}{|c|c|c|c|c|c|c|c|c|c|c|c|c|}
\hline & \multicolumn{6}{|c|}{ Day 10} & \multicolumn{6}{|c|}{ Day 15} \\
\hline & \multicolumn{2}{|c|}{ Control } & \multicolumn{2}{|c|}{ Sd-d4 } & \multicolumn{2}{|c|}{ Sp-d4 } & \multicolumn{2}{|c|}{ Control } & \multicolumn{2}{|c|}{ Sd-d4 } & \multicolumn{2}{|c|}{ Sp-d4 } \\
\hline & Mean & SD & Mean & SD & Mean & SD & Mean & SD & Mean & SD & Mean & SD \\
\hline Liver & 631.5 & $70 \cdot 0$ & $489.0^{*}$ & $24 \cdot 3$ & $488 \cdot 0^{*}$ & 51.5 & $1262 \cdot 0$ & 119.8 & $1222 \cdot 3$ & 9.3 & $1065 \cdot 3$ & $14 \cdot 1$ \\
\hline Spleen & 84.5 & 19.8 & 59.5 & 34.5 & 84.0 & 9.3 & 153.8 & $30 \cdot 6$ & $148 \cdot 3$ & 17.8 & $143 \cdot 5$ & 3.7 \\
\hline Kidneys & $254 \cdot 3$ & 43.6 & 197.8 & $15 \cdot 0$ & $202 \cdot 0$ & 17.9 & 429.8 & 19.9 & $387.5^{*}$ & 19.9 & $358.8 *$ & 17.7 \\
\hline Heart & 140.8 & $19 \cdot 1$ & 114.5 & 13.6 & $100 \cdot 5^{*}$ & $15 \cdot 0$ & $276 \cdot 5$ & $31 \cdot 2$ & $211 \cdot 5^{*}$ & 8.0 & $203.5 *$ & 9.6 \\
\hline
\end{tabular}

* Mean values were significantly different from those for the control group, $P<0.05$ (Student's two-tailed $t$ test).

$\dagger$ For details of procedures, see pp. 640-642. 
Day 10

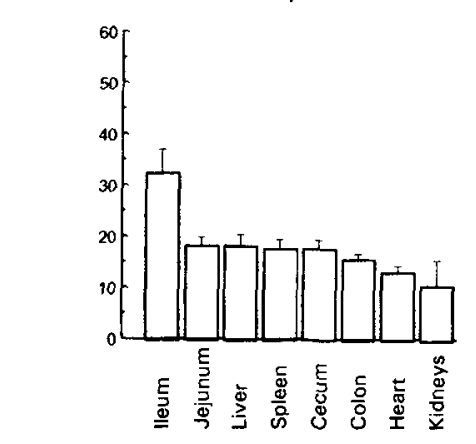

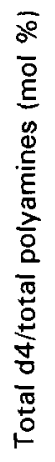

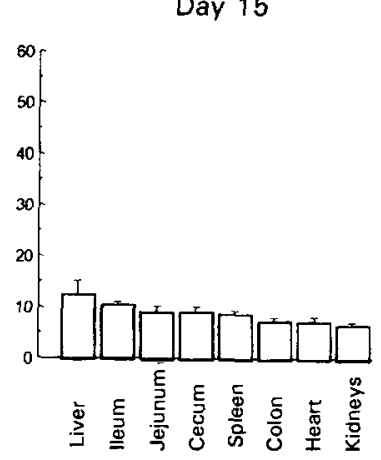

(a)

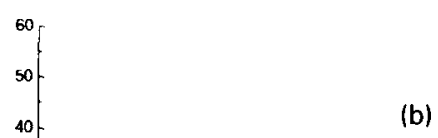

(b)

(c)

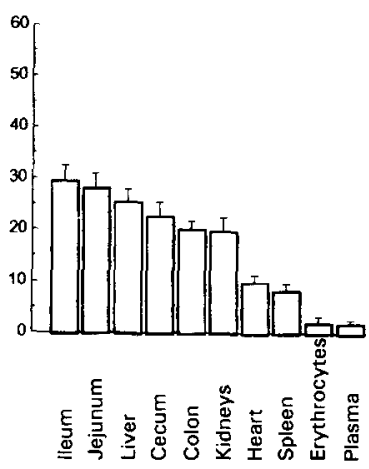

Fig. 1. Relative contributions of the sum of all deuterium-labelled (d4) polyamines to the total polyamine pools in various organs. Rat pups received $3 \mu \mathrm{mol}$ putrescine (Pu-d4) (panels (a)), $5 \mu \mathrm{mol}$ spermidine (Sd-d4) (panels (b)), or $3 \mu \mathrm{mol}$ spermine (Sp-d4) (panels (c)) twice daily on days 7-10 (left panels) or days 12-15 (right panels). The sum of all labelled polyamines is the sum of Pu-d4, Sd-d4 and Sp-d4. Values are means for four rat pups, with standard deviations represented by vertical bars.

generally increased in caecum and colon, whereas in jejunum and ileum they tended to decrease. Liver and kidneys showed divergent responses to the various treatments, whereas plasma, heart and spleen generally did not show major changes in their polyamine contents. Administration of either one of the labelled polyamines had caused a 6-7-fold increase of erythrocyte spermidine levels on day 10 . Putrescine contents increased 3.6-8.5-fold. These effects were not observed on day 15. Following administration of Pu-d4 from day 7-10, brain (in $\mathrm{nmol} / \mathrm{g}$; data not shown in Table 2) contained 42.7 (SD 7.9) Pu (control: 50.7 (SD 20.3)), 397.1 (SD 21.9) Sd (control: 414.3 (SD 79.2)), and 415.2 (SD 15.1) Sp (control: 


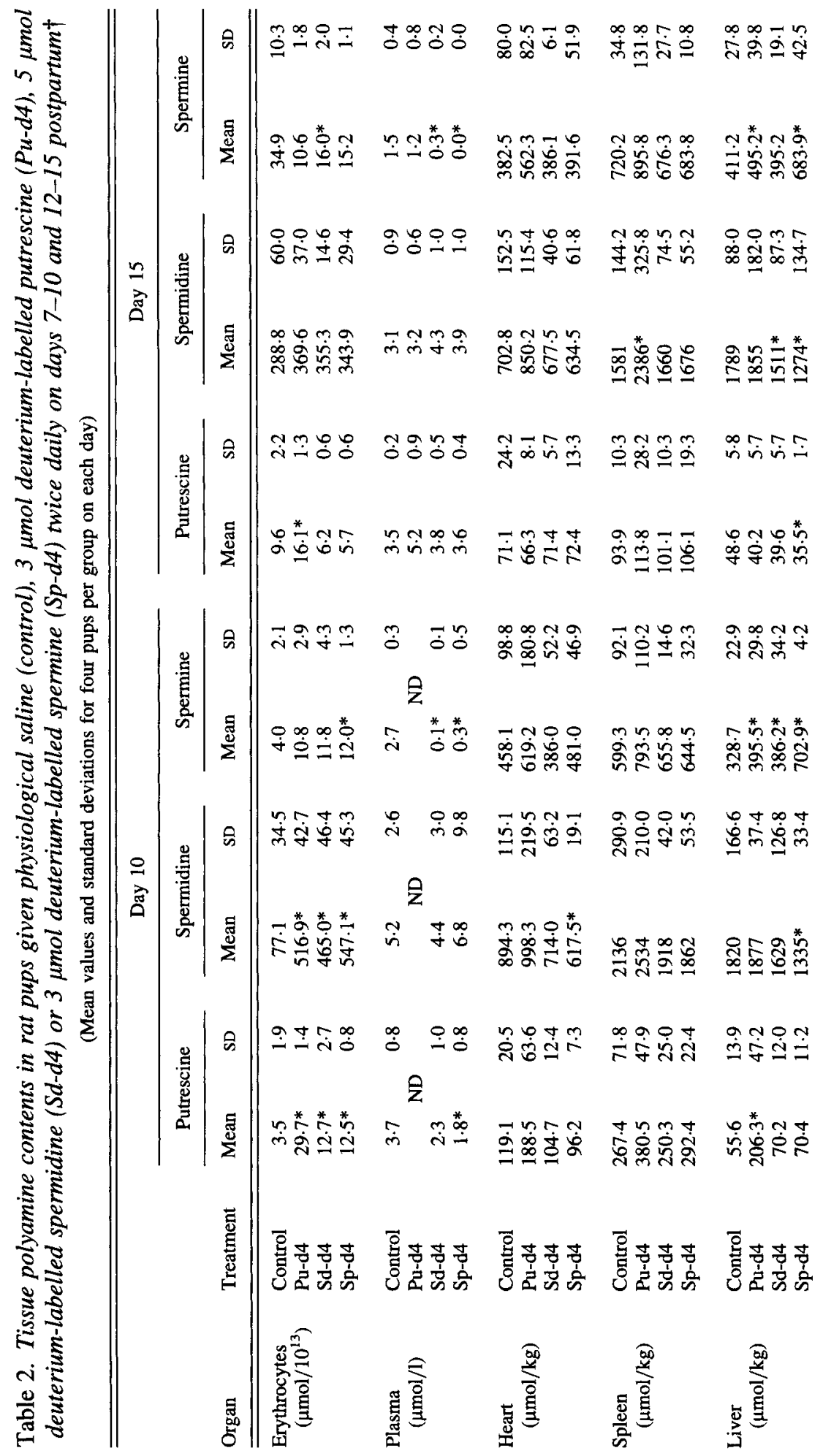




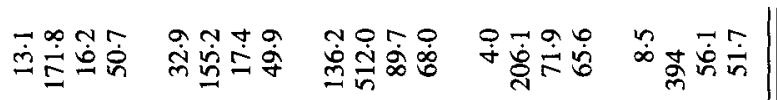

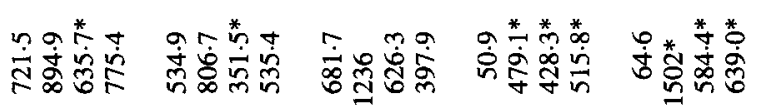

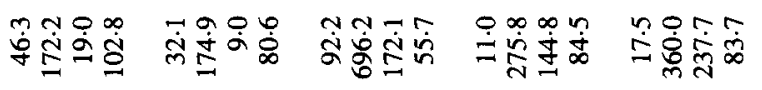

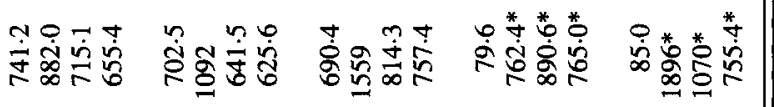

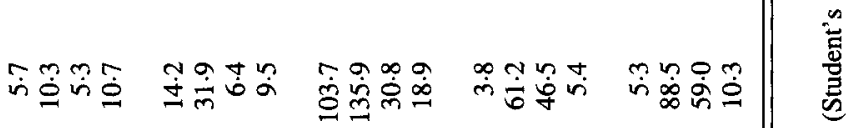

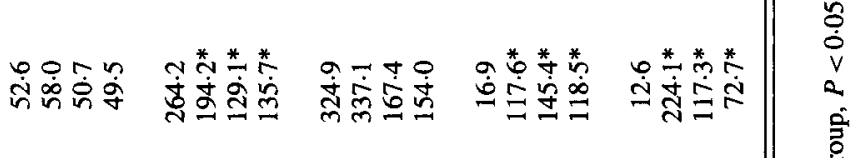

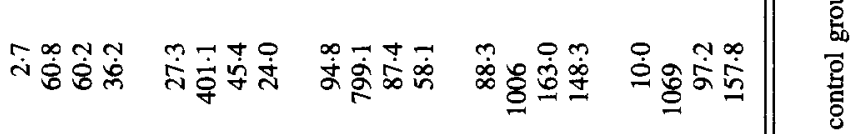

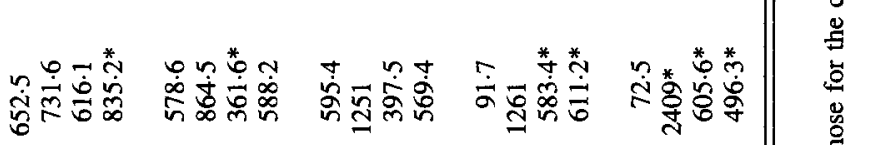

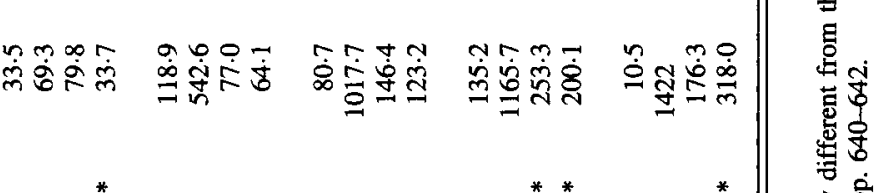

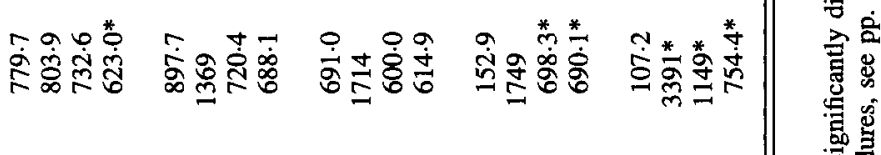

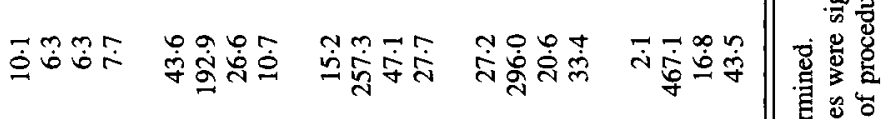

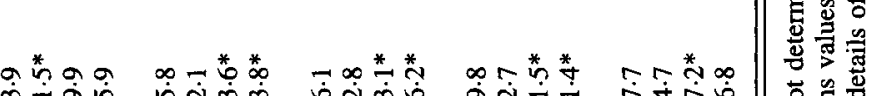

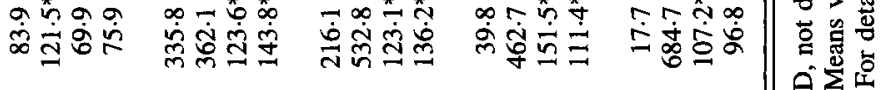

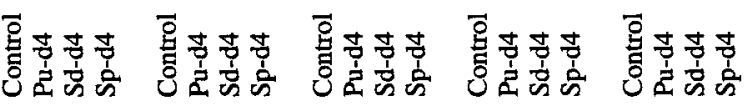

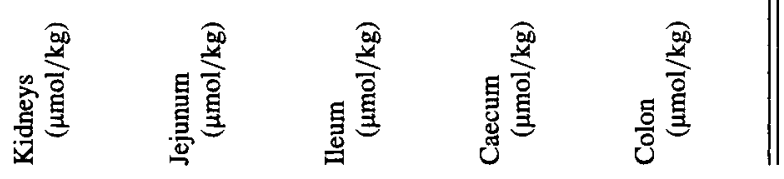


380.6 (SD 28.5)) on day 10. For Pu-d4 administration on days 10-15, these data were: 24.7 (SD 4.8) Pu (control: 22.4 (SD 4.1)), 404.6 (SD 105.5) Sd (control: 370.3 (SD 89.2)), and 425.8 (SD 15.2) Sp (control: 413.9 (SD 35.9)) on day 15. Brain polyamine contents did not change significantly in either treatment period.

\section{Metabolism of deuterium-labelled polyamines}

Fig. 2 shows the relative contributions of Pu-d4, Sd-d4 and Sp-d4 to the total deuteriumlabelled polyamine pools in the organs of rat pups that were treated with Pu-d4 (panel (a)), Sd-d4 (panel (b)) and Sp-d4 (panel (c)). Panel (a) shows that orally administered Pu-d4 was notably demonstrable as Sd-d4, and to a lesser extent as Pu-d4 and Sp-d4. The contribution
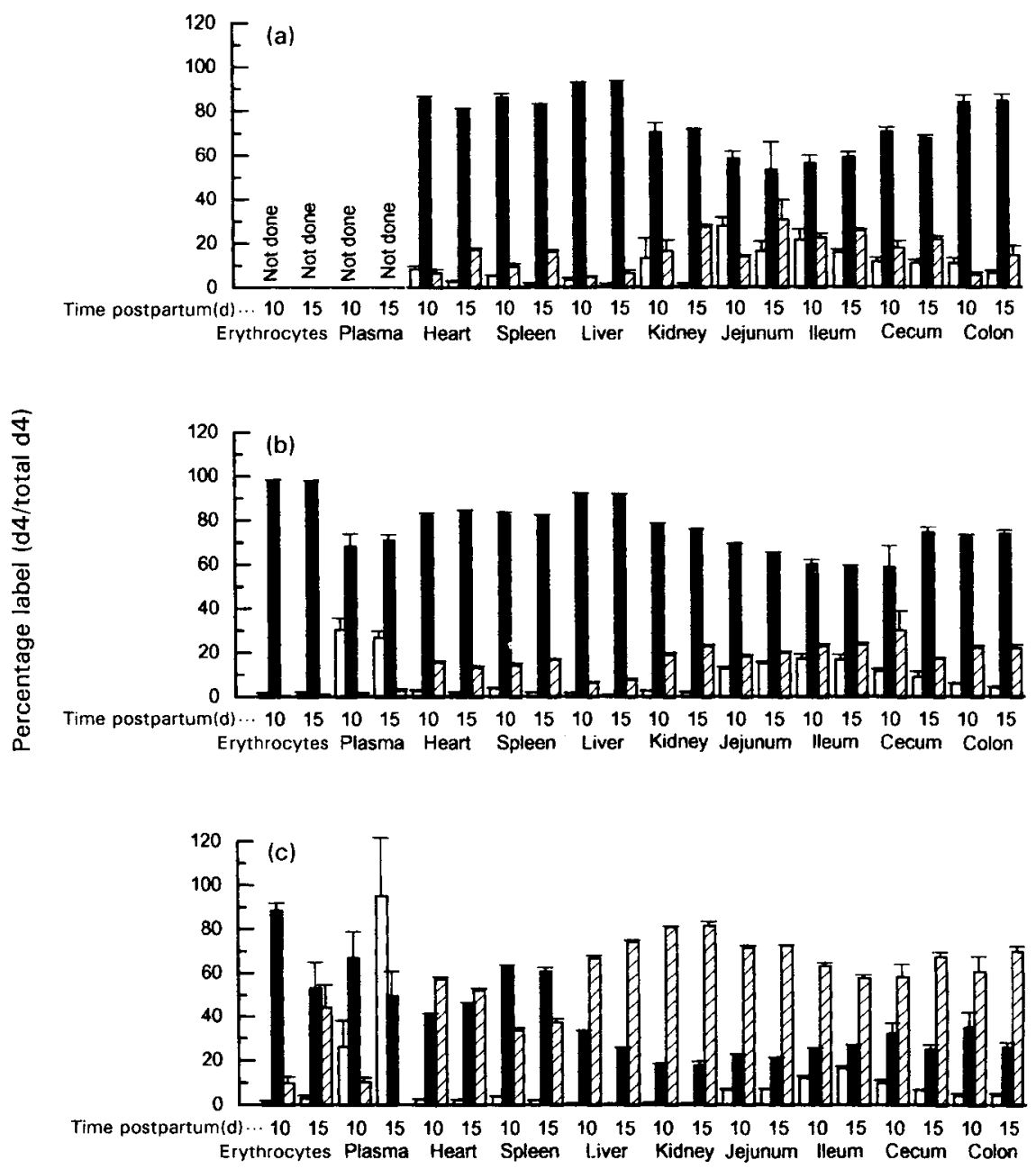

Fig. 2. Relative contributions of deuterium-labelled putrescine (Pu-d4, $\square$ ), spermidine (Sd-d4; $\square$ ) and spermine (Sp$\mathrm{d} 4 ; \mathrm{V}$ ) to the total deuterium-labelled polyamine pools in various organs. Rat pups received $3 \mu \mathrm{mol} \mathrm{Pu}-\mathrm{d} 4$ (panel (a)), $5 \mu \mathrm{mol} \mathrm{Sd-d4} \mathrm{(panel} \mathrm{(b)),} \mathrm{or} 3 \mu \mathrm{mol} \mathrm{Sp-d4} \mathrm{(panel} \mathrm{(c))} \mathrm{twice} \mathrm{daily} \mathrm{on} \mathrm{days} \mathrm{7-10} \mathrm{(indicated} \mathrm{by} 10$ on $\mathrm{x}$-axis) or days 12-15 (15 on $\mathrm{x}$-axis). Values are means for four rat pups, with standard deviations indicated by vertical bars. 
of Sd-d4 ranged from $53 \%$ (jejunum) to $92 \%$ (liver) of all deuterium-labelled polyamines. Following administration of Pu-d4, brain (not shown in Fig. 2) contained 6.9 (SD 2.4) \% Pu-d4, 79.3 (SD 1.8) \% Sd-d4 and 13.8 (SD 2.9) \% Sp-d4 on day 10, and 3.9 (SD 1.0) \% Pu$\mathrm{d} 4,80.1$ (SD 2.6) \% Sd-d4 and 16.0 (SD 3.3) \% Sp-d4 on day 15 .

Fig. 2(b) shows that orally administered Sd-d4 was predominantly recovered as Sd-d4 (58-98\%) in most organs. Gut tissue showed a wide distribution of deuterium label among the three polyamines, with higher relative contents of both Pu-d4 and Sp-d4, and consequently lower relative contents of Sd-d4 (58-74\%), compared with other tissues. Sd$\mathrm{d} 4$ represented $97-98 \%$ of total deuterium-labelled polyamines in erythrocytes, whereas plasma contained the highest percentage of Pu-d4.

Fig. 2(c) shows that orally administered Sp-d4 was predominantly found as Sp-d4 $(10-81 \%)$ in most organs. In erythrocytes Sd-d 4 comprised the majority ( $88 \%$ on day 10 , $53 \%$ on day 15 ) of total deuterated polyamines, whereas plasma contained the highest percentage of Pu-d4.

\section{Enzyme activities}

The activity of DAO in the ileum of the four PS-treated pups (controls) amounted to $1 \cdot 1$ (SD 0.4) $\mu \mathrm{mol} / \mathrm{min}$ per g protein on day 10 and 1.4 (SD 0.4) $\mu \mathrm{mol} / \mathrm{min}$ per g protein on day 15. DAO activity did not change as a function of postnatal age and did not change significantly as a result of polyamine administration (results not shown).

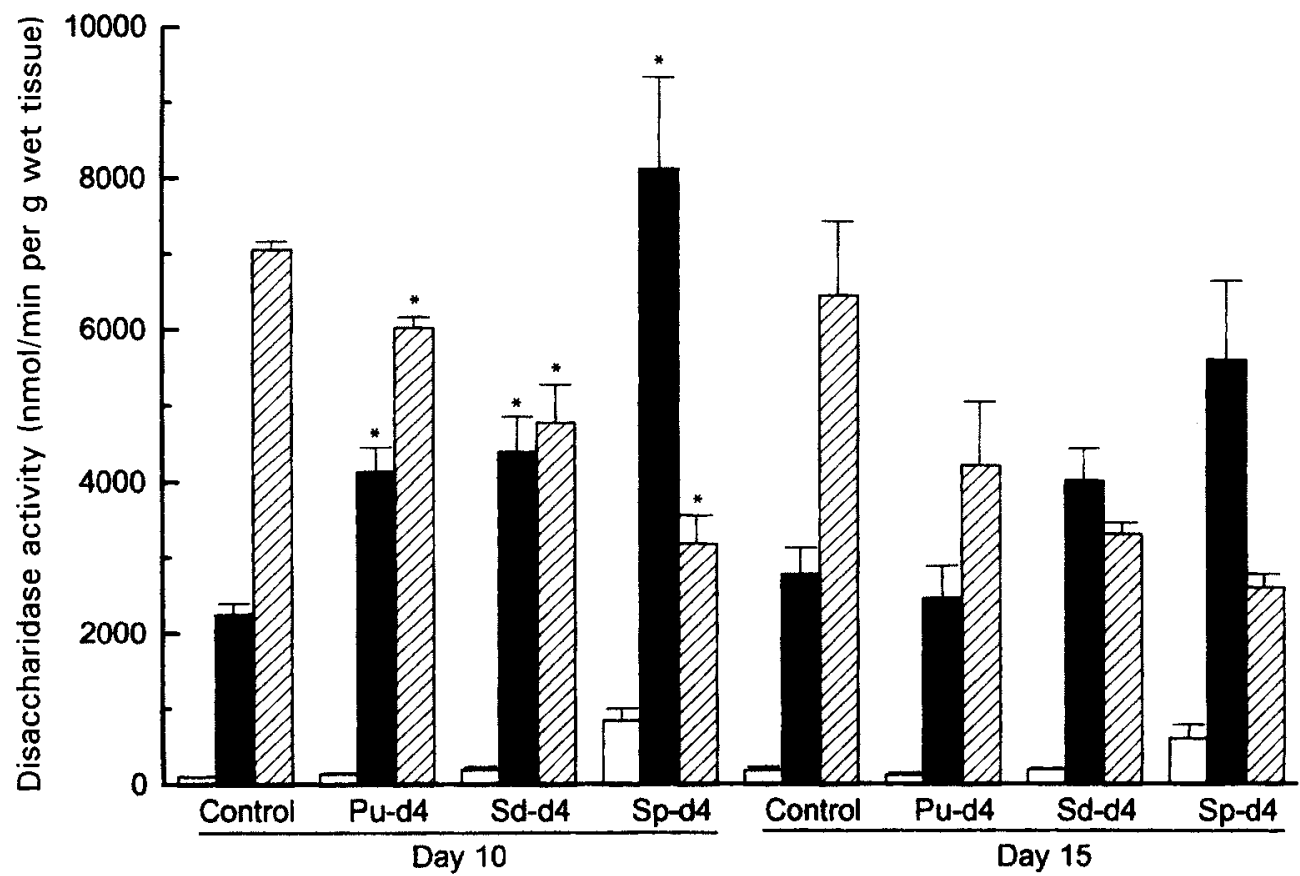

Fig. 3. Activities of sucrase ( $\square$ ), maltase (圈) and lactase $(\mathbb{C})$ in the ileum of rat pups. Rat pups received physiological saline (control) or deuterium-labelled polyamines: $3 \mu \mathrm{mol}$ putrescine (Pu-d4), $5 \mu \mathrm{mol}$ spermidine (Sd-d4), or $3 \mu \mathrm{mol}$ spermine (Sp-d4) twice daily on days 7-10, or days 12-15. Values are means for four rat pups, with standard deviations represented by vertical bars. * Mean values were significantly different from control by Student's $t$ test, corrected for type I errors $(P<0.05)$. 
Fig. 3 shows the activities of sucrase, maltase and lactase in the ileum of the rat pups. Compared with control, treatment with Pu-d4, Sd-d4 and Sp-d4 from day 7-10 increased the activity of maltase on day 10 . The activity of lactase decreased. Sucrase activity did not change to a statistically significant extent. Treatments on days 12-15 caused similar changes, but these changes did not reach statistical significance either.

\section{Morphology}

Fig. 4 shows villus and crypt lengths in the ileum of the rat pups. In the day 7-10 period, neither polyamine affected villus lengths, whereas Sd-d4 and Sp-d4 treatments increased crypt lengths. In the day 12-15 period, all three polyamines increased villus lengths, while $\mathrm{Sp}-\mathrm{d} 4$ increased crypt lengths. Following Pu-d4 and Sd-d4 treatments on days 12-15, villus : crypt ratios were significantly higher $(P<0.05)$ than control values $(\mathrm{Pu}-\mathrm{d} 4: 10.0(\mathrm{SD}$ 2.0); Sd-d4: 7.2 (SD 0.05); control: 5.9 (SD 0.05)).

\section{DISCUSSION}

The primary aim of the present study was to investigate organ distribution and metabolic fate of orally administered stable-isotopically labelled polyamines in rat pups. For this we

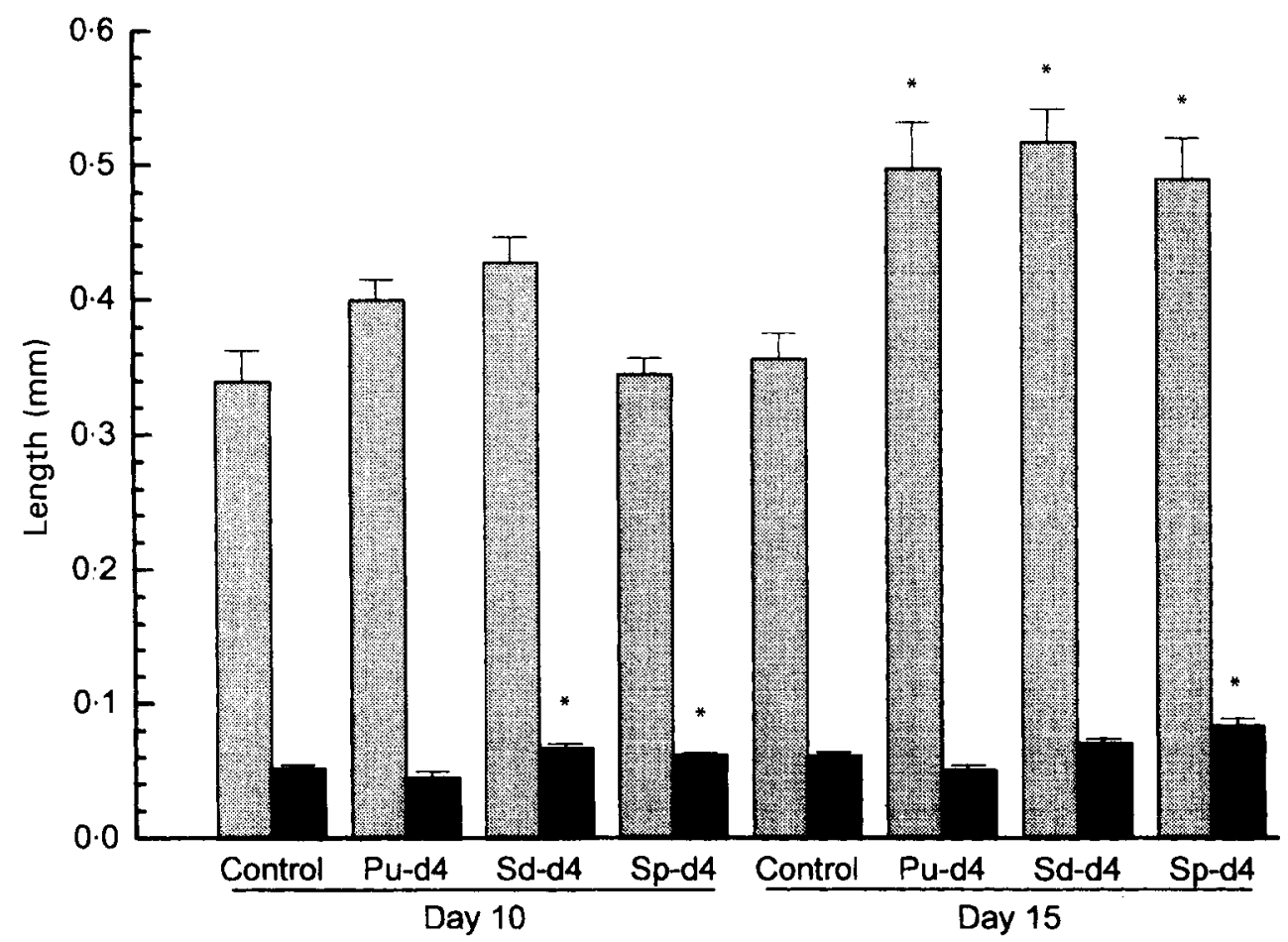

Fig. 4. Villus (圆) and crypt ( $\mathbf{\square}$ ) lengths in the ileum of rat pups. Rat pups received physiological saline (control), or deuterium-labelled polyamines: $3 \mu \mathrm{mol}$ putrescine ( $\mathrm{Pu}-\mathrm{d} 4), 5 \mu \mathrm{mol}$ spermidine ( $\mathrm{Sd}-\mathrm{d} 4$ ), or $3 \mu \mathrm{mol}$ spermine (Sp-d4) twice daily on days $7-10$, or days $12-15$. Values are means for four rat pups with standard deviations represented by vertical bars. * Mean values were significantly different from control by Student's $t$ test, corrected for type I errors $(P<0.05)$. 
used the protocol as described by Dufour et al. (1988), with some amendments. They used $5 \mu \mathrm{mol} \mathrm{Sd}$ and $3 \mu \mathrm{mol} \mathrm{Sp}$ (dissolved in $50 \mu \mathrm{l} \mathrm{PS}$ ), administered twice daily on postpartum days 12,13 and 14. We employed the same schedule and dose for Sd-d4 and Sp-d4, but also studied the effects of $3 \mu \mathrm{mol} \mathrm{Pu-d4}$. In addition, we studied the effect of $3 \mu \mathrm{mol} \mathrm{Pu}$ $\mathrm{d} 4,5 \mu \mathrm{mol} \mathrm{Sd}-\mathrm{d} 4$ and $3 \mu \mathrm{mol} \mathrm{Sp-d} 4$ (dissolved in $25 \mu \mathrm{l} \mathrm{PS}$ ) twice daily on postpartum days 7, 8 and 9. From the data of Pollack et al. (1992) it can be estimated that median daily polyamine intakes from milk by 13-14-d-old rat pups amount to $12 \mathrm{nmol}$ putrescine, $235 \mathrm{nmol}$ spermidine and $18 \mathrm{nmol}$ spermine. Polyamine intakes in the present study were, therefore, about 500, 43 and 333 times higher than the physiological intakes of putrescine, spermidine and spermine respectively.

Our observations on ileal disaccharidase activity and morphology are in agreement with the findings of Dufour et al. (1988), who showed that orally administered spermidine and spermine induce precocious gut maturation. In addition our results show that $3 \mu \mathrm{mol}$ $\mathrm{Pu}-\mathrm{d} 4$ twice daily causes similar effects. It suggests that GI maturation rate is restricted by limited availability of putrescine. In contrast to the results of Dufour et al. (1988) the effects on disaccharidase activities did not reach significance in the day 12-15 period, which may have been due to the relatively small number of animals. Significant changes were, however, found in the day 7-10 period. Changes in morphology were found to be statistically significant in both treatment periods. Increased villus lengths are in agreement with observations by Madsen et al. (1996), who reported that polyamines play an essential role in enterocyte mitochondrial function and integrity during migration from the crypt up the villus. We did not find concomitant changes of DAO activity. Rat intestinal DAO activity is known to increase in the day 14-21 postnatal period (Luk et al. 1980). The apparent discrepancy suggests that oral polyamines exert differential effects on the various aspects of gut maturation, and that the exogenous polyamines do not induce increased degradation of putrescine and cadaverine in the ileum.

Our results show that orally administered deuterium-labelled polyamines are not only taken up in the gut, but that they are distributed among all investigated organs, including brain, in both treatment periods. The organs showed large differences in the percentage of labelled polyamines (Fig. 1) and large differences with respect to the distribution of the label among putrescine, spermidine and spermine (Fig. 2). This shows that the administered polyamines are not merely used for the synthesis of higher polyamines, but that they are partially retroconverted to their precursors. Our results do not reveal in what organ(s) interconversion (i.e. the combination of biosynthesis and retroconversion) took place, since the encountered organ contents are the final result of many factors and dynamic processes, including extracellular concentrations, transport activity, intracellular trapping efficiency and terminal catabolism. Differences among organs may also partially derive from differences in their blood contents, since the blood compartment contains, notably, exogenous spermidine in erythrocytes, and spermidine and putrescine in plasma. Such contaminations may have affected the data of, notably, the spleen and liver.

The most striking results with respect to tissue polyamine contents and labelling percentages were found in the gut and erythrocytes. Jejunal and ileal polyamine contents remained unchanged, or even decreased, following polyamine administration (Table 2). The polyamine labelling percentages were, however, found to be relatively high, compared with other organs (Fig. 1), and the label was widely distributed among the three measured polyamines (Fig. 2). These observations can be explained by a highly effective displacement of unlabelled polyamines by labelled polyamines, but also by a process that causes immediate sharing of the labelled polyamines after uptake, e.g. between mother 
and daughter cells during cell division. The larger villi encountered in the ileum following polyamine administration (Fig. 4) strengthen the latter notion.

In contrast to small-intestinal tissues (jejunum and ileum), large-intestinal tissues (caecum and colon) showed dramatic increases in tissue polyamine contents (Table 2). The increase in large-intestinal polyamine contents could not be explained merely by the uptake of labelled polyamines, but proved predominantly to be due to accumulation of unlabelled polyamines. The underlying reason is unclear. The present findings, however, suggest that the large intestine handles exogenous polyamines differently from the small intestine, possibly because of differences in the need for exogenous polyamines for proliferation, or differences in apical to basolateral transport activity.

Erythrocyte spermidine contents of PS-treated rats (controls) on day 15 were almost four times higher than those on day 10 (Table 2). This increase may have coincided with increased erythropoiesis, as has been reported to take place from day 15 to day 20 after birth (Garcia, 1957; Garcia \& Van Dyke, 1961). Garcia \& Van Dyke (1961) showed that erythropoietin administration to rat pups on day 12 postpartum does not induce erythropoiesis, probably because at that stage bone marrow is functioning at maximum capacity. Erythrocyte polyamine levels have been shown to increase in the event of high erythrocyte turnover, e.g. in sickle cell disease and other haemoglobinopathies, and are positively correlated with the percentages of reticulocytes (Muskiet et al. 1991; Martina et al. 1993). Pups that received putrescine, spermidine or spermine on days 7-10 showed 6-7fold increases in erythrocyte spermidine contents on day 10 (Table 2). This increase could only partially (for approximately $10 \%$ ) be accounted for by the administered labelled polyamines (Fig. 1). The effect on spermidine levels was not observed on day 15. Taken together these observations suggest that oral administration of polyamines on days 7-10 induces processes in the erythropoietic system that usually take place at a later stage. More specifically, they are likely to cause erythropoiesis either directly or indirectly, followed by reticulocytosis.

It is concluded that the orally administered polyamines that cause precocious GI tract maturation in rat pups are distributed among all presently investigated organs, and that they are subject to interconversion. They may not only affect the GI tract but also many other tissues. One of these is the bone marrow, which may respond with precocious erythropoiesis. It should be pointed out that the present doses are well above the physiological polyamine intakes via rat milk. They did not seem to affect short-term growth rate, as compared with PS-treated animals, suggesting that they do not cause overt toxicity. Lower weight of some organs does not necessarily imply toxicity either, but this may be strengthened by measurement of indicators of organ function. Supplementation of (preterm) infant formula with polyamines may prove beneficial for various reasons, but further studies are warranted. For example, it remains to be established whether similar effects can be obtained by supplementation with ornithine and arginine as precursors of putrescine, i.e. whether the underlying mechanisms reflect a competition between the use of amino acids for protein synthesis or for their conversion to biologically active amines.

We thank Dr J. Koudstaal (Department of Pathology, State University Groningen, Groningen, The Netherlands) for his kind support with the morphometric measurements, $\mathrm{Mr} \mathrm{C}$. Baarveld (Department of Pathology, State University Groningen, Groningen, The Netherlands) for preparing the microscopic slides, and Mr M. Volmer (Central Laboratory for Clinical Chemistry, University Hospital, Groningen, The Netherlands) for carrying out the statistical evaluations. 


\section{REFERENCES}

Bardócz, S., Duguid, T. J., Brown, D. S., Grant, G., Pusztai, A., White, A. \& Ralph, A. (1995). The importance of dietary polyamines in cell regeneration and growth. British Journal of Nutrition 73, 819-828.

Biondi, P. A., Simonic, T., Secchi, C. \& Ronchi, S. (1984). Sensitive assay for diamine oxidase activity using high-performance liquid chromatography. Journal of Chromatography Biomedical Applications 309, 151155.

Buts, J. P., De Keyser, N., De Raedemaeker, L., Collette, E. \& Sokal, E. M. (1995). Polyamine profiles in human milk, infant artificial formulas, and semi-elemental diets. Journal of Pediatric Gastroenterology and Nutrition 21, 44-49.

Buts, J. P., De Keyser, N., Kolanowski, J., Sokal, E. \& Van Hoof, F. (1993). Maturation of villus and crypt cell functions in rat small intestine. Digestive Diseases and Sciences 38, 1091-1098.

Capano, G., Bloch, K. J., Schiffrin, E. J., Dascoli, J. A., Israel, E. J. \& Harmatz, P. R. (1994). Influence of the polyamine, spermidine, on intestinal maturation and dietary antigen uptake in the neonatal rat. Journal of Pediatric Gastroenterology and Nutrition 19, 34-42.

Dahlqvist, A. (1964). Method for assay of intestinal disaccharidases. Analytical Biochemistry 7, 18-25.

Dorhout, B., Van Beusekom, C. M., Huisman, M., Kingma, A.W., De Hoog, E., Boersma, E. R. \& Muskiet, F. A. J. (1996). Estimation of 24-hour polyamine intake from mature human milk. Journal of Pediatric Gastroenterology and Nutrition 23, 298-302.

Dufour, C., Dandrifosse, G., Forget, P., Vermesse, F., Romain, N. \& Lepoint, P. (1988). Spermine and spermidine induce intestinal maturation in the rat. Gastroenterology 95, 112-116.

Garcia, J. F. (1957). Changes in blood, plasma and red cell volume in the male rat, as a function of age. American Journal of Physiology 190, 19-24.

Garcia, J. F. \& Van Dyke, D. C. (1961). Response of rats of various ages to erythropoietin. Proceedings of the Society for Experimental Biology and Medicine 106, 585-588.

Gonnella, P. A., Siminoski, K., Murphy, R. A. \& Neutra, M. R. (1987). Transepithelial transport of epidermal growth factor by absorptive cells of suckling rat ileum. Journal of Clinical Investigation 80, 22-32.

Harada, E., Hashimoto, Y. \& Syuto, B. (1994). Orally administered spermine induces precocious intestinal maturation of macromolecular transport and disaccharidase development in suckling rats. Comparative Biochemistry and Physiology 109A, 667-673.

Hasegawa, H., Nakamura, A., Watanabe, K., Brown, W. R. \& Nagura, H. (1987). Intestinal uptake of IgG in suckling rats. Gastroenterology 92, 186-191.

Hessels, J., Kingma, A. W., Ferwerda, H., Keij, J., Van den Berg, G. A. \& Muskiet, F. A. J. (1989). Microbial flora in the gastrointestinal tract abolishes cytostatic effects of $\alpha$-difiuoromethylornithine in vivo. International Journal of Cancer 43, 1155-1164.

Jansen, G., Muskiet, F. A. J., Schierbeek, H., Berger, R. \& Van der Slik, W. (1986). Capillary gas chromatographic profiling of urinary, plasma and erythrocyte sugars and polyols as their trismethylsilyl derivatives, preceded by a simple and rapid prepurification method. Clinica Chimica Acta 157, $277-294$.

Jones, E. A. \& Waldman, T. (1972). The mechanism of intestinal uptake and transcellular transport of IgG in the neonatal rat. Journal of Clinical Investigation 51, 2916-2927.

Lowry, O. H., Rosebrough, N. J., Farr, A. L. \& Randall, R. J. (1951). Protein measurement with the Folin phenol reagent. Journal of Biological Chemistry 193, 265-275.

Luk, G. D., Bayless, T. M. \& Baylin, S. B. (1980). Diamine oxidase (histaminase). A circulating marker for rat intestinal mucosal maturation and integrity. Journal of Clinical Investigation 66, 66-70.

Madsen, K. L., Brockway, P. D., Johnson, L. R., Hardin, J. A. \& Gall, D. G. (1996). Role of ornithine decarboxylase in enterocyte mitochondrial function and integrity. American Journal of Physiology, Gastrointestinal and Liver Physiology 33, G789-G797.

Martina, W. V., Martijn, E. G., Van der Molen, M., Schermer, J. G. \& Muskiet, F. A. J. (1993). $\beta$-N-Terminal glycohemoglobins in subjects with common hemoglobinopathies: relation with fructosamine and mean erythrocyte age. Clinical Chemistry 39, 2259-2265.

Muskiet, F. A. J., Muskiet, F. D., Meiborg, G. \& Schermer, J. G. (1991). Supplementation of patients with homozygous sickle cell disease with zinc, $\alpha$-tocopherol, vitamin C, soybean oil, and fish oil. American Journal of Clinical Nutrition 54, 736-744.

Nsi-Emvo, E., Chaton, B., Foltzer-Jourdainne, C., Gosse, F. \& Raul, F. (1996). Premature expression of sucraseisomaltase triggered by corticoid-dependent changes in polyamine metabolism. American Journal of Physiology, Gastrointestinal and Liver Physiology 33, G54-G59.

Osborne, D. L. \& Seidel, E. R. (1990). Gastrointestinal luminal polyamines: cellular accumulation and enterohepatic circulation. American Journal of Physiology 258, G576-G584.

Pegg, A. E. \& McCann, P. P. (1982). Polyamine metabolism and function. American Journal of Physiology 243, C212-C221.

Pollack, P. F., Koldóvsky, O. \& Nishioka, K. (1992). Polyamines in human and rat milk and in infant formulas. American Journal of Clinical Nutrition 56, 371-375. 
Romain, N., Dandrifosse, G., Jeusette, F. \& Forget, P. (1992). Polyamine concentration in rat milk and food, human milk, and infant formulas. Pediatric Research 32, 58-63.

Sarhan, S., Knödgen, B. \& Seiler, N. (1989). The gastrointestinal tract as polyamine source for tumor growth. Anticancer Research 9, 215-224.

Satink, H. P. W. M., Hessels, J., Kingma, A. W., Van den Berg, G. A., Muskiet, F. A. J. \& Halie, M. R. (1989). Microbial influences on urinary polyamine excretion. Clinica Chimica Acta 179, 305-314.

Seiler, N., Bolkenius, F. N. \& Rennert, O. M. (1981). Interconversion, catabolism and elimination of the polyamines. Medical Biology 59, 334-346.

Seiler, N. \& Dezeure, F. (1990). Polyamine transport in mammalian cells. International Journal of Biochemistry 22, 211-218.

Smith, R. G. \& Daves, G. D. (1977). Gas chromatography mass spectrometry analysis of polyamines using deuterated analogs as internal standards. Biomedical Mass Spectrometry 4, 146-151.

Stevens, J. (1986). Applied Multivariate Statistics for the Social Sciences. New Hillside, NJ: LEA.

Van den Berg, G. A., Elzinga, H., Nagel, G. T., Kingma, A. W. \& Muskiet, F. A. J. (1984). The catabolism of polyamines in the rat. Polyamines and their non- $\alpha$-amino acid metabolites. Biochimica et Biophysica Acta 802, 175-187.

Van den Berg, G. A., Kingma, A. W. \& Muskiet, F. A. J. (1987). Determination of polyamines in human erythrocytes by capillary gas chromatography with nitrogen-phosphorus detection. Journal of Chromatography Biomedical Applications 415, 27-34. 